\title{
Smart Irrigation System using IOT
}

\author{
Shiv Shankar Singh
}

\begin{abstract}
The agriculture sector is biggest sector of India it provides employment to $50 \%$ work force of India. Each and every sector of India is directly or indirectly connected to agriculture sector, despite of this the development in technology is very less. Farmers are still using conventional techniques for farming, the developed technologies are either expensive or does not required by farmer. In this paper a Smart irrigation system is discussed which is economical and have great impact on irrigation system. The system controlled in two modes first is manual and second is automatic control for controlling the operation of water pump. The pump is controlled by using Atmega328P IC which is programmable in nature using relay as switch and taking the feedback from soil moisture sensor and rain sensor for controlling the water pump. The manual control is done by using HTML webpage by BOLT IoT module.
\end{abstract}

Keywords - agriculture, farmer, sector, irrigation, manual, automatic, control, Atmega328P, soil moisture sensor, rain sensor, relay, water pump, cloud, BOLT.

\section{INTRODUCTION}

The cloud control technology is developing with fast pace and entering each and every sector and drastically improving the condition of sector[1]. The cloud and IoT technology in recent year entered agriculture and by using these two technologies the farmer is increasing production and reducing cost. In this paper a system is discussed which uses both cloud and IoT technologies for controlling the irrigation system[2][3]. The system discussed comprises many elements for performing specific task. A BOLT IoT module is used for receiving commands from user and transmitting data to cloud server for analysing, the BOLT module is connected with Atmega328P for controlling the system which is further connected with soil moisture sensor which send data regarding water contain of soil for controlling water pump and a rain sensor for sensing rain, if sensor senses rain then control unit stops the water pump for saving energy and saving crop from excess water. The BOLT module sends data to cloud and a graphical representation of sensed data is shown to user automatically

\section{TECHNOLOGIES USED}

Atmega328P: The Atmega328P IC is a programmable microcontroller IC which is used for taking input from sensors and controlling the connected electrical units to it. The Atmega328P is programmed in $\mathrm{C}, \mathrm{C}++$ language by using Arduino IDE software[4]. The Atmega328P have digitalwrite pins for digital input and output and analogwrite pins for analogue input and output[5][6].

\footnotetext{
Revised Manuscript Received on August 05, 2019.

Shiv Shankar Singh, Department of Computer Science and Engineering, Sanskriti University, Uttar Pradesh, India. (E-mail: sanpubip@gmail.com)
}

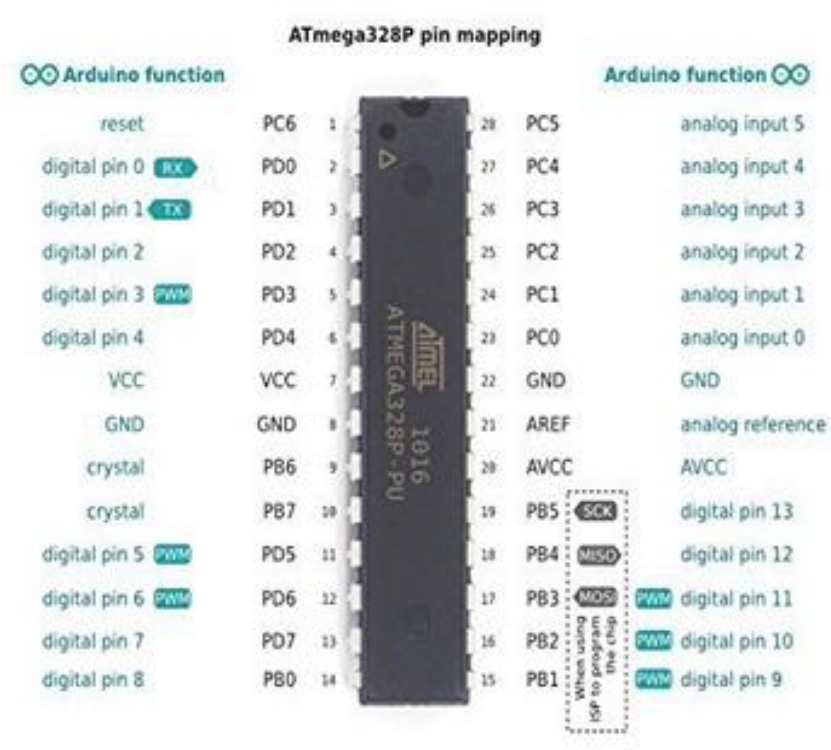

Figure 1: Atmega328P

FC-28: The FC-28 is soil moisture measurement sensor which is used with Arduino Uno. The working principle of FC-28 is very simple, it detects the resistance of soil, when soil contain more water it conductivity of current will increase i.e. less resistance and when the soil contain less water it will conduct less current resulting in high resistance. Thus by calculating the current flow we can detect the moisture of soil[7].

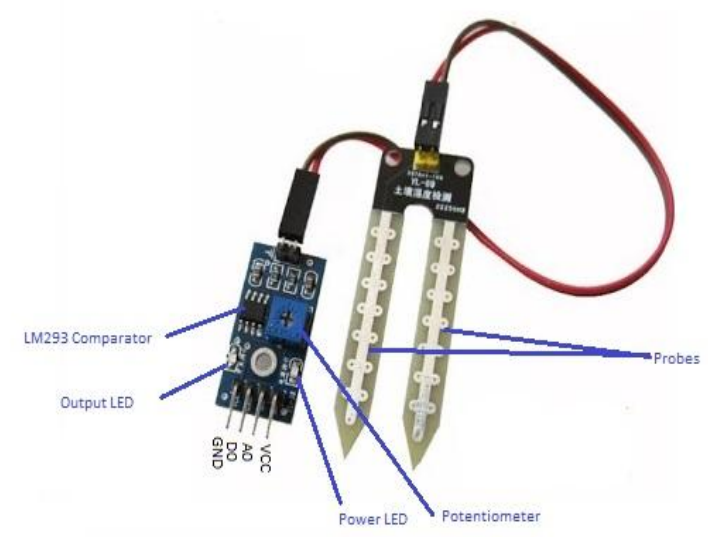

Figure 2: FC-28

BOLT IoT module: The BOLT module is an IoT based module designed by BOLT, this module is internet of things hardware and software platform. This enables users to build IoT based projects. The BOLT provides a cloud platform for save data online which can be accessed by user anywhere with internet connectivity[8]. 


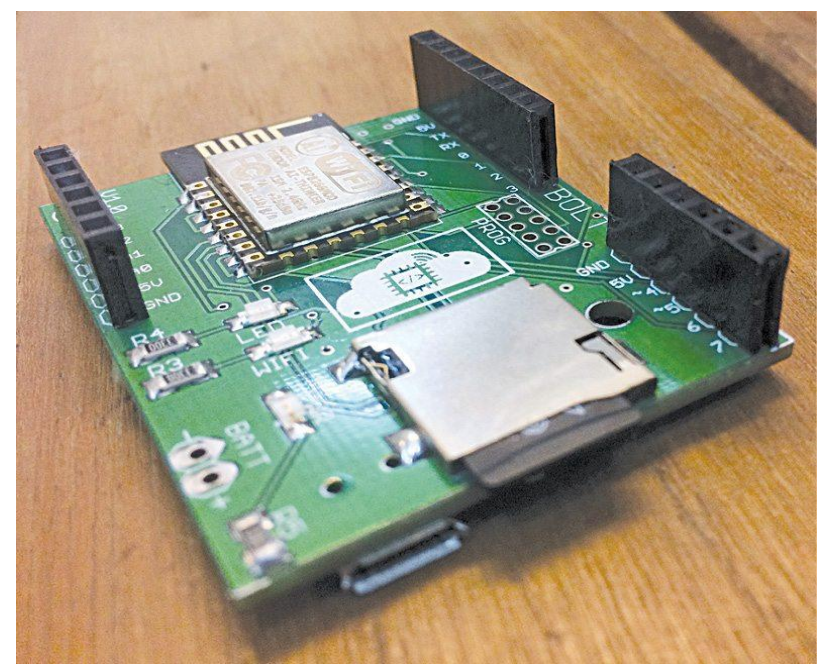

Figure 3: BOLT IoT Module

Rain Sensor: The rain sensors detects the rain, the basic principle of working is checking resistance of sensor, and the sensor comprises two different conduction printed leads on whole surface. When water droplets fall on surface of sensor it completes the circuit and thus creating a resistance which is far less than open circuit resistance of sensor and the sensed data is sent to controlling unit[9].

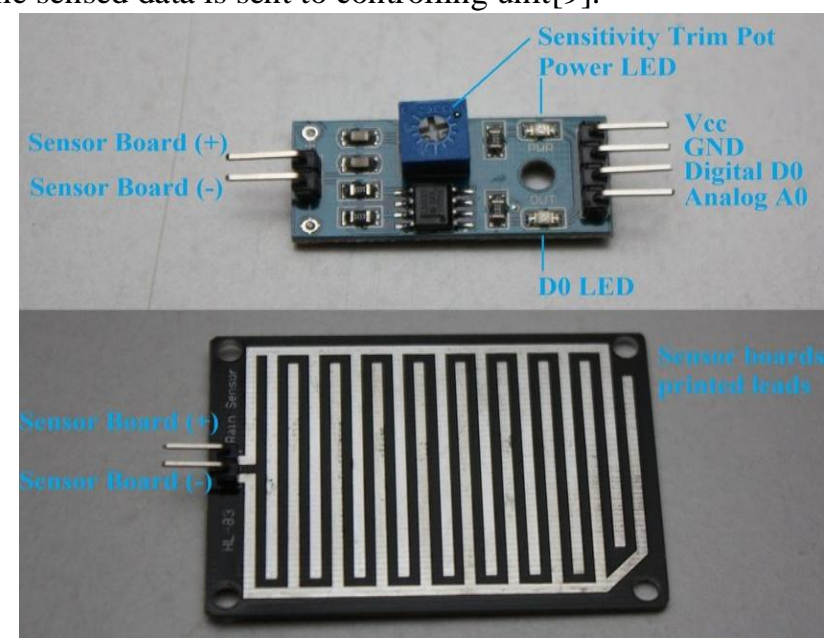

Figure 4: Rain sensor

Mechanical Relay: The mechanical relay is a device which act as a switch in a circuit. The mechanical relay works on the principle of electromagnetic induction, when current passes through coil of relay it creates the magnetic field which attracts the conduction plate and when the flow of current stops the coil releases the conduction plate this mechanism provides the switching operation to relay[10].

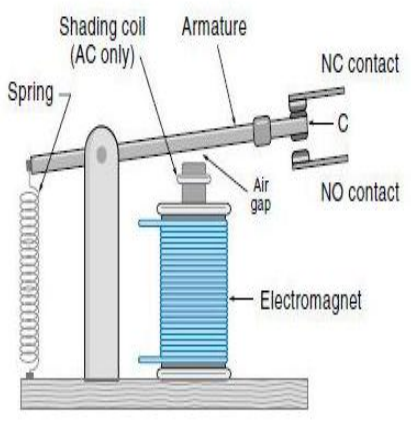

(a)

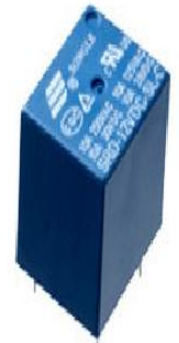

(b)
Figure 5: (a) Schematic Representation of mechanical relay (b) Mechanical Relay

\section{PROPOSED SYSTEM}

The proposed system comprises a Atmega328P IC which is the control unit of whole system, a moisture sensor is connected with Atmega328P which is senses the amount of water in soil, a rain sensor for sensing the rain connected with the Atmega328P, a BOLT module for saving the sensed data on remote location and provides remote control of system via internet and relay which is controlled by Atmega328P IC and the relay provides the switching operation for turning on/off motor for pumping water[11].

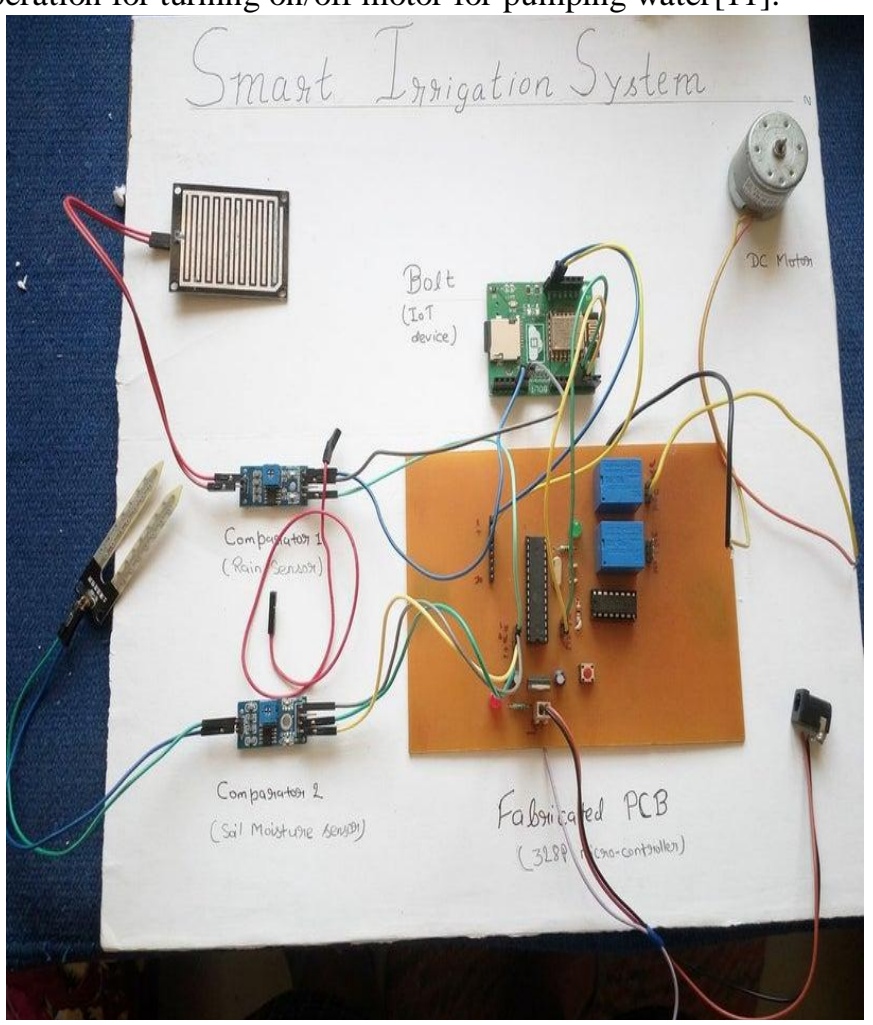

Figure 6: Prototype of proposed system

\section{WORKING OF SYSTEM}

The BOLT module receives command from the user via internet using HTML webpage regarding turning on/off the system.

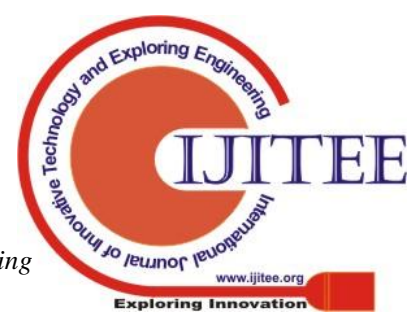




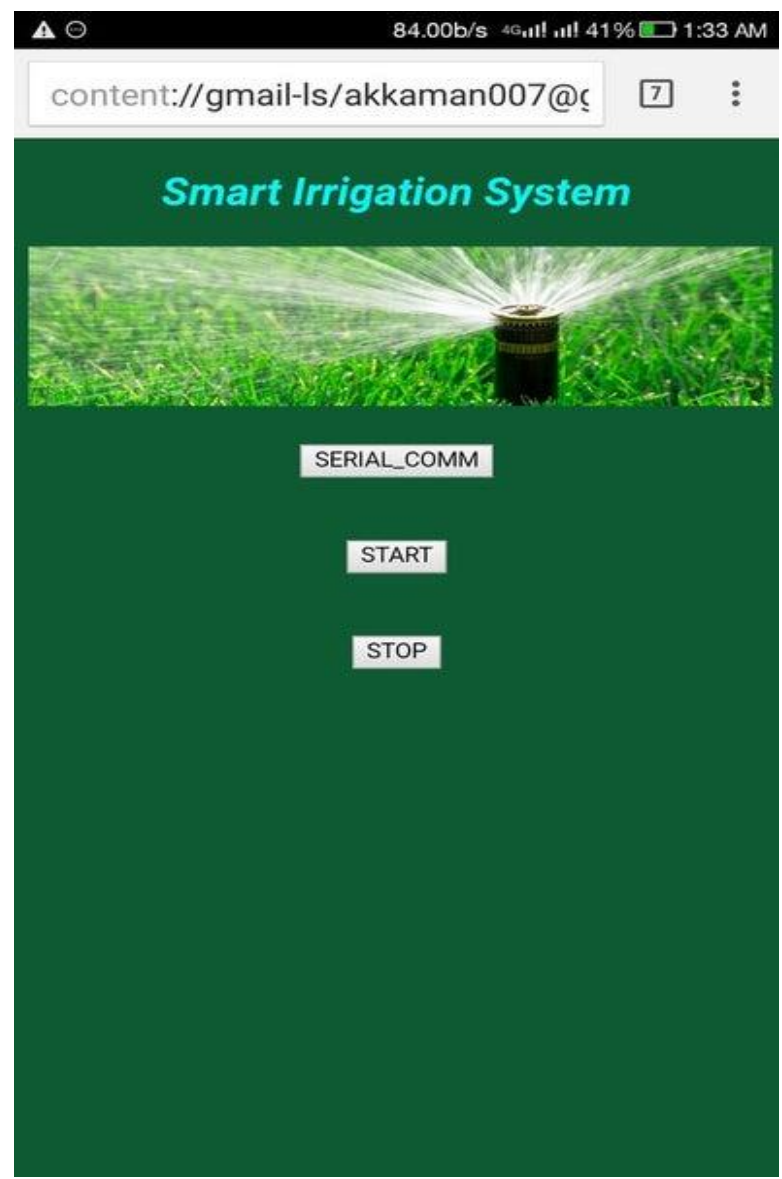

Figure 7: HTML webpage

After receiving command from user the system check the soil moisture using sensor and depending upon the readings of sensor system starts the water pump or motor. If soil contain sufficient water then the control won't start the motor.

The rain sensor continuously checks for rain. If rain starts the sensor detects and send signal to control unit and the control unit stops the water pump or motor depending on the sensor data.

The control unit continuously sends sensors data to cloud storage using BOLT module and generates graphical representation of the data
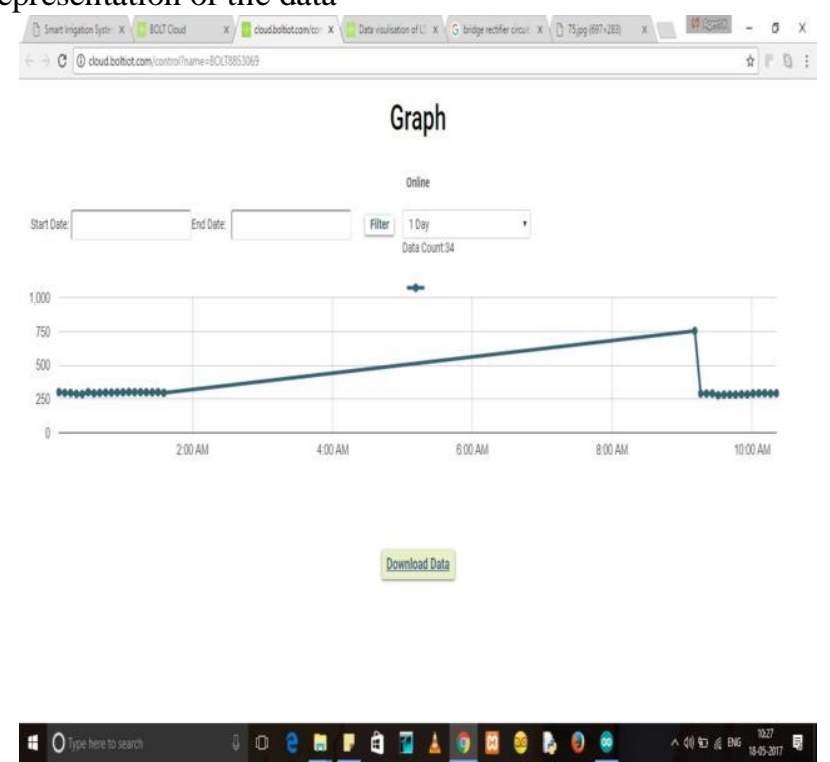

Figure 8: Graphical representation of sensed data on cloud

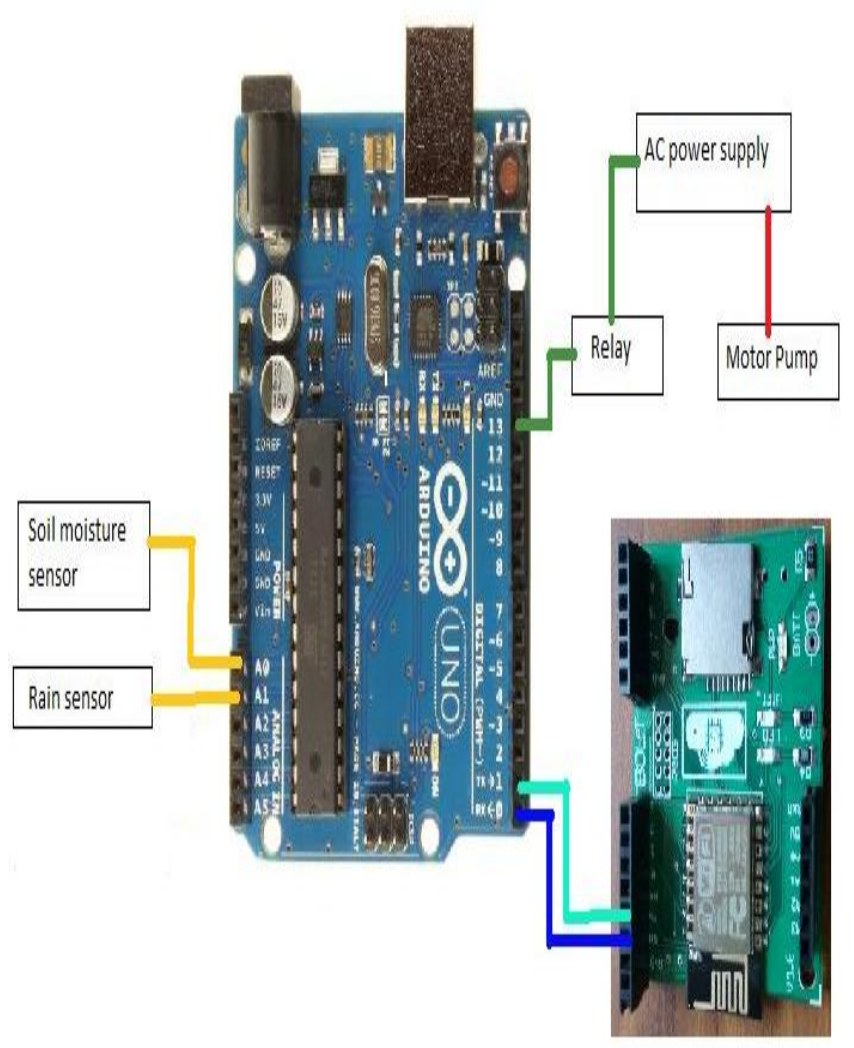

Figure 9: Components connection representation

\section{RESULT}

The system is tested in real life conditions on a farm field for 60 days in rainy season. The system works properly and sensed the soil moisture, rain and the control unit act accordingly to sensed data and control the water pump.

\section{CONCLUSION}

The system worked as designed and planned, it optimally control the water pump and highly reduced the electricity consumption of farm by $30 \%$ and the production of farm is increased by $17.23 \%$ because of controlled water supply to crops. In future more sensors will be implemented for controlling the water pump and for collection of different climatic condition data for analysing and improving the farming

\section{REFERENCES}

1. S. Marston, Z. Li, S. Bandyopadhyay, J. Zhang, and A. Ghalsasi, "Cloud computing - The business perspective," Decis. Support Syst., 2011.

2. F. T. -, "Smart Agriculture Based on Cloud Computing and IOT," J. Converg. Inf. Technol., 2013.

3. M. S. Mekala and P. Viswanathan, "A Survey: Smart agriculture IoT with cloud computing," in 2017 International Conference on Microelectronic Devices, Circuits and Systems, ICMDCS 2017, 2017.

4. S. A. Arduino, "What is Arduino?," Arduino Doc., 2015.

5. A. V. R. Microcontroller, "ATmega328P," Atmel, Data Sheet. 2015.

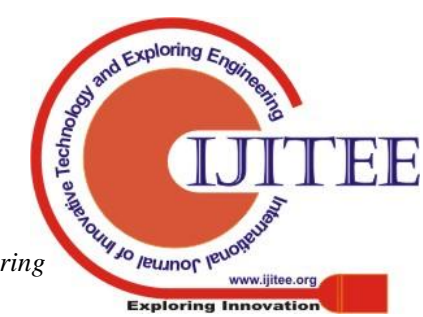


6. D. Wheat and D. Wheat, "Arduino Software," in Arduino Internals, 2012.

7. H. Eller and A. Denoth, "A capacitive soil moisture sensor,” J. Hydrol., 1996.

8. P. Asthana and S. Mishra, "IoT Enabled Real Time Bolt based Indoor Air Quality Monitoring System," in 2018 International Conference on Computational and Characterization Techniques in Engineering and Sciences, CCTES 2018, 2019.

9. B. J. Bos, K. Schofield, and M. L. Larson, "Rain sensor," US Patent 6,313,454. 2001.

10. V. Pott, H. Kam, R. Nathanael, J. Jeon, E. Alon, and T. J. King Liu, "Mechanical computing redux: Relays for integrated circuit applications," in Proceedings of the IEEE, 2010.

11. P. Yang, "Wires on water," Nature, 2003. 